4

\title{
TRES PAPAS CONTRA NINGÚN DEMONIO (LA DIMENSIÓN POLÍTICA EN DISCURSOS DEL PAPA FRANCISCO)
}

THREE POPES AGAINST NO DEVIL

(POLITICAL ASPECT OF SOME SPEECHES BY POPE FRANCIS)

Alexis Dóvganj

petrovich@gmail.com; esletras@ffyh.unc.edu.ar /

Lic. en Letras Modernas por la Universidad Nacional de Córdoba, docente en la Dirección General de Educación Superior de la Provincia de Córdoba.

Fecha de recepción

$>16 / 05 / 20$
Fecha de aceptación

$>12 / 06 / 20$ 


\section{RESUMEN}

Este artículo comenta mi investigación de grado sobre el carácter político de la enunciación lingüística en el discurso del papa Francisco I, en concreto, en tres alocuciones de carácter oficial pronunciadas por este en el marco de su visita a México en 2016. El punto de partida teórico es un recorrido sobre distintas concepciones del signo, hasta llegar al modelo ternario propuesto en «La semiosis social», de Eliseo Verón. Dado este marco general, analizamos el corpus mediante categorías específicas para el análisis de discurso político, en especial, aquellas relativas al dispositivo de enunciación. Nuestro análisis presupone la posibilidad de establecer una dimensión política inherente a todo discurso social, no solo a aquéllos considerados políticos en términos descriptivos. En esta dimensión, el enunciador del discurso papal tiende una red de relaciones de poder con sus lectores, distinguiendo entre los enunciatarios con los que se identifica positivamente, los que reprueba de todo punto y los que intenta convencer de emprender nuevas acciones. Este esquema de hacer-hacer se legitima en la axiología polarizada entre el bien y el mal y el principio de necesidad de la justicia divina que, desde La Biblia, opera como condición de producción de todo el discurso papal.

\section{PALABRAS CLAVE}

$>$ enunciación

$>$ México

$>$ papa Francisco I

$>$ política

$>$ semiótica 


\section{ABSTRACT}

This article comments on my research about the political nature of linguistic enunciation in speeches of Pope Francis I, specifically, in three official addresses delivered by him in his visit to Mexico in 2016. Our theoretical framework starts at a comment on different conceptions of signs, until arriving at the ternary model proposed in La semiosis social, by Eliseo Verón. Given this general framework, we analyze the corpus through categories specific to analyze political discourse, especially those related to the enunciation device. Our analysis presupposes the possibility of establishing a political dimension inherent in all social discourse, not only those considered political in descriptive terms. In this dimension, the pope tends a network of power relations with its readers, distinguishing between enunciators by his side, adversaries and undecided, those he tries to convince to take new actions. This scheme of manipulation is legitimized by the polarized axiologybetween good and evil and the principle of necessity of divine justice that, from The Bible, operates as a condition of production for the entire papal discourse.

\section{KEYWORDS}

$>$ enunciation

$>$ México

$>$ politics

$>$ pope Francis I

$>$ semiotics 


\section{UNAS PALABRAS SOBRE LA PALABRA}

El discurso bíblico, como matriz de la religión católica, atribuye su emisión a un sujeto de conocimiento absoluto que resuelve la discontinuidad entre «representación de la realidad» y «verdad», en la medida en que sus enunciados se proponen como un reflejo directo del Universo, conocido absoluta y positivamente; en ellos existe un nutrido metadiscurso que representa la palabra como intermediario inocuo, necesario para encarnar «la verdad» tal cual es y revelársela al hombre imperfecto. La Biblia cuenta «cosas» inmutables, que la preexisten eternamente, más allá de toda interpretación, es decir, más allá de toda palabra:

Los profetas nunca hablaron por iniciativa humana; al contrario, eran hombres que hablaban de parte de Dios, dirigidos por el Espíritu Santo. (Sociedades Bíblicas Unidas, 2000:1335)

La desconexión del discurso bíblico de sus condiciones de producción crea una ilusión de sentido único, en el que la palabra parece tener una relación frontal con su objeto. Esto constituye lo que Verón llama «efecto ideológico» del discurso (1993:23). Pero, lejos de ser unívocas, las connotaciones de un signo lingüístico son erráticas, y, fundamentalmente, diversas. El sentido se produce siempre en condiciones disímiles, al punto en que los productos de una «inteligencia semiótica»s son hipotéticamente infinitos (Peirce, 1987:244).

En consecuencia, toda fijación del sentido propuesta para un signo deberá ser introducida, invariablemente, por otro signo que explique el primero y funcione a manera de recomendación de lectura. El carácter político de los enunciados lingüísticos emerge como una militancia en esa recomendación de lectura:

Pero ante todo tengan esto presente: ninguna profecía de la Escritura es algo que uno pueda interpretar según el propio parecer (....). (Sociedades Bíblicas Unidas, 2000: 1335)

La posición que adopta el enunciador del texto bíblico respecto al enunciatario genérico «ustedes» (luego restringido a la intimidad personal del «propio parecer» de «uno») determina relaciones de poder entre el locutor y su auditorio: aquellos que obedezcan la recomendación de lectura reciben sanción positiva, en 
tanto que los rebeldes deben ser combatidos. En síntesis, el enunciador predica la defensa de una axiología que discierne entre enunciatarios buenos y malos.

En todo hecho de lengua, el aparato formal de la enunciación ofrece los primeros indicios de posiciones divergentes en el discurso lingüístico, axiomas lógicos infranqueables, presupuestos en todo enunciado: el enunciador se ubica en la coordenada «0» de tiempo y espacio, hic et nunc. Los demás tiempos, actores y espacios difieren necesariamente de este punto de origen a partir del cual se desarrolla la deixis (Benveniste, 1970).

Sobre la base de este algoritmo gramatical, como interface elemental para la comunicación lingüística, se desarrollan conceptos de mayor abstracción. El sistema de la lengua funciona como conjunto básico de condiciones de producción del discurso. En él, el enunciador cuenta con una serie de opciones sobre las cuales elige cómo construir sus enunciados.

Del campo de la lingüística aplicada, Verón toma prestado el término «gramática», mediante el cual no se refiere a las reglas que distinguen lo gramatical de lo agramatical, sino a discursos, representaciones de la realidad que sirven como punto de partida para la construcción y la lectura de nuevos enunciados. Así, los rasgos propios de la tipología de los discursos aparecen como una sobrecodificación de los elementos formales del sistema lingüístico.

\section{TODO TEXTO ES POLÍTICO}

Lo dicho sobre los tipos de discurso remite a la vieja oposición analítico vs. descriptivo. Con arreglo a criterios netamente descriptivos, el discurso político es un conjunto bien definido de textos, caracterizado por un tema regular (la administración de instituciones gubernamentales del estado) y unos enunciadores específicos (los denominados "políticos», candidatos partidarios y autoridades consumadas). Por el contrario, conforme a un criterio analítico, Triquell y Ruíz (2014) postulan «lo político» en tanto dimensión de análisis subyacente a toda clase de discursos, no solo descriptivamente políticos. 
(...) si la distinción entre «la ideología/lo ideológico» refiere a las condiciones de producción y la de poder institucional/poder del discurso a las condiciones de reconocimiento, con la distinción entre la política/lo político queremos dar lugar a una determinada relación del discurso con el mundo al que refiere y que pretende no meramente representar - en una relación de transparencia - sino más bien constituir en objeto del pensamiento. Se trataría acá de la relación del signo con el objeto, relación que no se limita a las condiciones de reconocimiento. (Triquell y Ruíz, 2014: 132)

La propuesta de Triquell y Ruíz apunta a las relaciones entre los discursos y sus objetos, según las diferentes representaciones que se ponen en circulación en reconocimiento. Estas relaciones tienen la forma de otros discursos que, en tanto interpretantes del primero, juzgan la manera en que este representa a su objeto (Triquell y Ruíz, 2014). Siguiendo esta línea de pensamiento, nuestra investigación se constituye en interpretante del discurso papal, en tanto describe la red de relaciones que el enunciador mantiene con su auditorio.

\section{AMIGOS, ENEMIGOS E INDECISOS}

Siguiendo a Verón (1996), analizamos las interacciones textuales entre el enunciador, por un lado, y tres clases de enunciatarios posibles en una lectura política del discurso papal. ${ }^{1}$ Primero, nos referimos al prodestinatario, el gran «nosotros», partidario cristiano, feligrés, hermano, oveja del rebaño. En segundo lugar, hablamos del contradestinatario anticristiano, apóstata, irredimible, negado a todo sermón. Finalmente, dedicamos un apartado al paradestinatario, dueño de una indecisión que el enunciador intentará transformar en adhesión a su causa.

Tres textos componen nuestro corpus: el Discurso protocolar en el Palacio Nacional de México (A), pronunciado por Francisco a su arribo, ante autoridades gubernamentales y representantes de la sociedad civil mexicana; la Misa en el área de la Feria de Ciudad Juárez (B), homilía signada por la situación fronteriza

\footnotetext{
${ }^{1}$ En La palabra adversativa, Verón postula además una serie de entidades y componentes estratégicos para la enunciación política, los cuales exceden el texto de esta reseña.
} 
de Juárez con respecto a los Estados Unidos de América (EUA) y la escalada de violencia entre carteles narcotraficantes; y la Conferencia de prensa en el vuelo de regreso a Roma (C), en la que el papa respondió, como es habitual, las preguntas de corresponsales periodísticos de todo el mundo, expresándose acerca de los pormenores de su visita a México, pero también sobre otros temas dictados por la agenda periodística especializada en asuntos vaticanos. Esta selección de textos presupone roles temáticos bien diferentes: en la conferencia, Francisco es un actor de los medios de prensa, específicamente, es un entrevistado, interlocutor necesario de los periodistas. En la homilía de Juárez, es líder de los sacerdotes católicos dando misa en un pueblo fervorosamente cristiano. En el discurso protocolar usufructúa el estatuto ambiguo de jefe de gobierno del Estado Vaticano y autoridad máxima de la Iglesia Católica Apostólica Romana (en adelante, ICAR). Conforme a las posiciones lógicas presupuestas para la enunciación política presentadas más arriba, los textos del corpus guardan notables similitudes y diferencias que confirman y amplían nuestras presuposiciones sobre los roles temáticos mencionados.

\section{OIGA, SEÑOR PRESIDENTE}

Una estrategia del enunciador de A (más notable en B) consiste en el borramiento de la autorreferencia. En el discurso protocolar, la alusión del papa a sí mismo se reduce a una breve serie de caracterizaciones que ubican a Francisco en un lugar de humilde subordinación, como hijo de Dios, peregrino y misionero de misericordia y paz. La «misión» evangelizadora convierte al papa en instrumento para la transmisión de los dones celestiales, no por iniciativa propia, sino por estricto mandato divino. Dejarse persuadir por el humilde misionero Francisco es aceptar la voluntad de Dios de llevar paz y misericordia a México.

El enunciatario del texto A oscila entre individuos específicos y colectivos de individuos. El discurso protocolar comienza con un largo vocativo que abarca a representantes políticos, civiles y religiosos, pero también público en general, «señoras, señores». El enunciatario positivo, con el que el enunciador comparte el pronombre «nosotros», son «los que nos llamamos cristianos», y a ellos co- 
rresponde, antes que, a nadie, aceptar y ejecutar el mandato de construir «una política auténticamente humana», es decir, en beneficio de todos. La ponderación del hacer propiamente cristiano es un tópico regular en todo el corpus; para un cristiano, la mejor manera de reafirmar su creencia es aceptar el desafío altruista de convertirse en benefactor del género humano, aceptando e invitando a aceptar el don de la misericordia divina (La Santa Sede, 2018: s.p.).

Junto a este enunciatario cristiano prepersuadido encontramos un paradestinatario amplio que, en principio, coincide con la denominación genérica «ustedes», a la que pertenecen todos los actores enumerados en el saludo inicial. Hacia este auditorio en pleno, el papa Francisco dirige una serie de constataciones: México es un país rico en culturas y naturalezas diversas, pero el egoísmo de «unos pocos» es una amenaza de destrucción sin remedio que debe ser combatida. Todos están invitados por Francisco a trasponer el egoísmo y así «valorar, estimular y cuidar» las riquezas mexicanas. Este es el punto álgido del discurso papal. A partir de aquí, la denominación colectiva del enunciatario gira abruptamente hacia la individualización de un único interlocutor: «En su persona, señor presidente (...)». En adelante opera un juego de parte por el todo en el que Francisco se dirige al pueblo mexicano a través de su líder político de mayor jerarquía. Al hacerlo, apunta a conmover ${ }^{2}$ a Peña Nieto, informándole calamidades especialmente superlativas (narcotráfico, tráfico de personas, muerte) para cuya solución ofrece la ayuda de la ICAR. El presidente de la república, autoridad de máximo poder ejecutivo, es por definición el único actor con capacidad de hacer para transformar el bien en mal y, al dirigirse personalmente a él, el papa arrincona toda posibilidad de cambio al ámbito de la voluntad del presidente. Así, la continuidad en los disvalores tendrá dos causas posibles: la falta de voluntad para hacer el bien, sea por ineptitud, sea por inoperancia de Peña Nieto; o, mucho peor, la voluntad del presidente para hacer el mal, suscribiendo de plano la propagación del crimen, la prevalencia de la muerte (La Santa Sede, 2018: s.p.).

Conforme a este panorama, no llama la atención que el comentario general de buena parte de la prensa mexicana haya considerado el discurso protocolar como una dura reprimenda del papa contra Enrique Peña Nieto. Sin embargo, aunque

\footnotetext{
${ }^{2}$ Las palabras de este Papa, en especial en la misa, pero también en los otros textos, tienen un fuerte componente pasional en el que se describen situaciones nefastas mediante semas de cantidad ingente.
} 
lo regaña, es obvio que no lo considera su enemigo. De hecho, el enunciador no construye en su discurso ningún adversario concreto: la alusión a «unos pocos» egoístas es por completo inespecífica. En consecuencia, el auditorio textual de este discurso se compone de partidarios, por un lado y posibles partidarios, por otro, de manera tal que basta con ser humano para poder dejarse convencer por el papa Francisco.

Hasta aquí hemos comentado «lo político» como dimensión de análisis en un texto descriptivamente político con respecto a su género solemnemente protocolar y a su foro primario, una reunión oficial de autoridades. Nuestra investigación busca expandir la lectura política a otros tipos textuales, tal es el caso que sigue.

\section{LA HOMILÍA EN CIUDAD PECADO}

Al pronunciar la misa en Ciudad Juárez, el papa evita referirse a sí mismo, salvo por un saludo parroquial que hace a la vecindad de uno y otro lado de la frontera con los EUA, cuando toma la palabra para reconocer el trabajo de un grupo de feligreses, hacia el final de la homilía. En todos los demás casos donde es el sujeto sintáctico de la cláusula, lo es junto a sus fieles: «Pidámosle a Nuestro Dios el don de la conversión». Así, mientras evita señalarse como individuo, estrecha su vínculo con la feligresía, toda vez que dice participar de su misma incapacidad de cambiar si no es por gracia divina. La invitación a reafirmar los votos evangélicos alcanza a un papa que insiste en su humilde humanidad (La Santa Sede, 2018: s.p.).

Más allá de esta comunión sintáctica de fieles y sacerdote, el papa sabe algo más que su auditorio y ha venido a denunciarlo: Juárez es una plaza regida por mafias sanguinarias que trafican personas y droga. Pero no todo está perdido: en tiempos antiguos hubo una ciudad llamada Nínive, tanto o más impía que Juárez, que fue bendecida por Dios con el don de la misericordia, el cual los ninivitas aceptaron, arrepintiéndose de los pecados en su corazón. La buena nueva de Francisco termina diciendo que el remedio a los males de Nínive también está disponible para Juárez. 
En su versión ${ }^{3}$ personificada, la misericordia

invita a la conversión, invita al arrepentimiento; invita a ver el daño que a todos los niveles se está causando (La Santa Sede, 2018: s.p.).

En este enunciado es notable la indefinición en cuanto al destinatario de la invitación, lo que autoriza a pensar que está dirigida a cualquiera capaz de oír el mensaje. Crece así el campo de los paradestinatarios, aquellos a quienes el papa quiere convencer: basta ser humano para quedar al alcance de la misericordia de Dios.

Pese a lo tétrico de sus constataciones sobre el delito y la muerte, Francisco evita perfectamente la construcción de enemigos, también en este texto. La regularidad de esta estrategia va tornándose notable y, en el último texto, ya es una constante.

\section{EL PAPA FRANCISCO EN VIVO}

En la conferencia de prensa del Santo Padre durante su viaje de regreso de México a Ciudad del Vaticano, el enunciador depone su estrategia de no-autorreferencia en favor de una profusa descripción de sí mismo y un extenso recuento de sus actividades. El cambio de estrategia es muy evidente, los pronombres de primera persona «me» y "yo» (escaso el primero e inexistente el segundo en el resto del corpus) se repiten con mayor frecuencia que ningún otro lexema subrayado 4 en nuestro análisis. De esta manera el sujeto de enunciación de la conferencia de prensa tiene un par muy activo a nivel del enunciado: el papa se reúne con sus hermanos, los abraza y los besa, les ofrece su ayuda, les aconseja la paz. Además de hacer todas estas cosas, "yo» también se autodefine «hermano», «humano», «extranjero» y «político» (La Santa Sede, 2018: s.p.).

\footnotetext{
${ }^{3}$ En este texto, en términos actanciales, «misericordia» es unas veces objeto destinado por Dios y, otras, sujeto que opera la transformación del mal en bien.

${ }^{4}$ Para identificar sistemáticamente todas las huellas de enunciación en los textos del corpus empleamos la aplicación informática TextSTAT, desarrollada por la Freie Universität de Berlín, que agiliza el análisis de recurrencia y concordancia de voces.
} 
Como hermano, humano y extranjero, el papa Francisco es, en este texto, un humilde par de sus pares. Como político, es un sujeto axiologizado, dispuesto a construir y defender representaciones de la realidad según valores bien organizados. El papel de los periodistas frente a este papa-político es indagar en su posicionamiento, interrogándolo acerca de sus deseos, sus motivaciones y sus planes. En sus respuestas a estas preguntas, Francisco no puede evitar aludir a dos campos semánticos cruciales para la persuasión del auditorio: muchas de las respuestas papales relatan experiencias privadas («he tenido un encuentro con las víctimas», "hemos tenido un coloquio de una hora»), en tanto que otras revelan hechos íntimos: "Sueño con imágenes (...). Mi psicología es así», "China... Me gustaría ir allá». En estas revelaciones, Francisco destaca su calidad de testigo privilegiado, dueño de un saber directo sobre el mundo en tanto vio y oyó in situ lo que cuenta y, al mismo tiempo, estrecha su vínculo de empatía con el auditorio, contándole intimidades (La Santa Sede, 2018: s.p.).

Este auditorio es el único restringido de todo el corpus. Formalmente, todos los indicios textuales del enunciatario corresponden a la segunda persona, siempre en plural, la cual hemos identificado en otras marcas textuales como «los periodistas». No hay «nosotros» cristiano» ni otro prodestinatario. No hay adversarios de la fe. Tampoco hay referencia a los misterios divinos o al arrepentimiento, de manera que lo que tiene este texto de persuasivo no apunta a la propagación del dogma.

En su agenda pública, los periodistas (también llamados comunicadores sociales) se postulan como buscadores seriales de «la verdad» de los hechos. El conocimiento directo de la fuente de información es la piedra angular de la objetividad, como valor supremo de la práctica periodística. Los periodistas a bordo del avión, junto al papa, tienen acceso privilegiado, no a presenciar los hechos que el papa les cuenta, sino a la versión oficial sobre esos hechos de la voz más autorizada de la Iglesia. Pero este enunciador no se presenta como sacerdote propalador de revelación divina, sino como un ser humano dispuesto a contar la humilde verdad de lo que ha visto y oído, de lo que siente y desea. 


\section{MISA EST (ALGUNAS CONCLUSIONES)}

El título de este artículo adelanta una conclusión relevante: el papa Francisco no tiene enemigos. Su peregrinación transatlántica no es una guerra santa, es una misión de misericordia y paz. Sin embargo es evidente que lo anticristiano tiene reservado un lugar considerable en el discurso de la ICAR. En el tiempo presente, el demonio y sus acólitos son enemigos irredimibles de la fe y tienen sentencia firme de muerte. En el futuro también serán enemigos consumados por la derrota aquellos seres humanos que hayan rechazado hasta la última oferta de misericordia, condenándose al castigo eterno. Nada de esto hay en el Evangelio según Francisco, que organiza todas sus palabras para militar una verdad que convenza a todos sus auditorios.

En estos textos, hemos pensado la construcción de la verdad en términos descriptivos y también analíticos. En el primer caso nos referimos estrictamente a los misterios divinos, un cuerpo de saberes específicos que deben ser aceptados como verdaderos sin objeción, pero, sobre todo, sin mediación de silogismos persuasivos. Descriptivamente, hay una región del discurso que constituye en sí misma la verdad. Tener fe es, por definición, aceptar que esa verdad es la verdad, más allá de toda contingencia, más allá de toda palabra. Naturalmente, la misión de todo sacerdote católico es garantizar la reproducción de esta manera de imponer verdad.

Analíticamente, podemos expandir la manera de concebir la verdad como la configuración de un gesto político dispuesto a convencer, más allá del objeto concreto de cada discurso. La puesta en marcha de esta estrategia requiere deponer el hábito religioso por un instante en beneficio de una matriz de conocimiento humana antes que divina. Junto a las pautas clásicas de verosimilitud del relato, el papa despliega los rasgos de su humanidad, capitalizándolos en un juego de persuasión que alcanza a todos sus pares humanos, acepten o no la verdad revelada. En sus respuestas a los periodistas, en lugar de imponer conocimientos herméticos inopinables, Francisco acepta las reglas de la moral massmediática y juega al juego de la objetividad, convirtiéndose en un enunciador capaz de una verdad mucho más versátil que un sacerdote en su púlpito.

Un corolario de los objetivos de este trabajo fue la puesta a prueba de falsación de las categorías pensadas por Verón para el discurso político en su aplicación 
sobre otros géneros de discurso. Lejos de probar el fracaso del método, la ausencia constante de adversarios en los enunciados de este papa se perfila como un patrón específico de su discurso. En este sentido, quedamos a las puertas de una nueva manera de concebir tipologías discursivas, ya no conforme a rígidas descripciones de contenido, sino mediante un análisis de regularidades estratégicas en la manipulación del auditorio.

\section{BIBLIOGRAFÍA}

Benveniste, E. (1970). El aparato formal de la enunciación. En Langages, año 5, №17, págs. 12-18.

La Santa Sede (2018). Viaje apostólico del Papa Francisco a México (12-18 de febrero de 2016). Conferencia de prensa del Santo Padre durante el vuelo de regreso a Roma. Recuperado de http://w2.vatican.va/content/francesco/es/speeches/2016/february/documents/papafrancesco_20160217_messico-conferenza-stampa.html el 31/05/18.

(2018). Viaje apostólico del Papa Francisco a México (12-18 de febrero de 2016). Encuentro con las autoridades, la sociedad civil y el cuerpo diplomático. Discurso del Santo Padre. Recuperado de http://w2.vatican.va/content/francesco/es/speeches/2016/ february/documents/papafrancesco_20160213_messico-autorita.html el 31/05/18.

(2018). Viaje apostólico del Papa Francisco a México (12-18 de febrero de 2016). Santa misa. Homilía del Santo Padre. Área de la feria de ciudad Juárez. Miércoles 17 de febrero de 2016. Recuperado dehttp://w2.vatican.va/content/francesco/es/ homilies/2016/documents/papafrancesco_20160217_omelia-messico-ciudad-jaurez. html el 31/05/18.

Peirce, C. (1987). Obra lógico-semiótica. Madrid: Taurus.

Triquell, X. y Ruíz, S. (2014). La dimensión política de los discursos sociales, De signos y sentidos, Santa Fe (Argentina), págs. 123-136.

Verón, E. (1993). La semiosis social. Barcelona: Gedisa.

(1996). «La palabra adversativa». Verón, E. et al., El discurso político. Lenguajes y acontecimientos. Buenos Aires: Hachette. 